\title{
Morphometric Analysis of the External Aperture of the Carotid Canal in Skulls of South Indian Origin
}

\author{
Siddharth Tewari ${ }^{1} \quad$ Chandni Gupta $^{2} \quad$ Vikram Palimar $^{3} \quad$ Sanjana Aithal ${ }^{1}$ \\ ${ }^{1}$ Kasturba Medical College, Manipal Academy of Higher Education, \\ Manipal, Karnataka, India \\ 2 Department of Anatomy, Kasturba Medical College, Manipal \\ Academy of Higher Education, Manipal, Karnataka, India \\ 3 Department of Forensic Medicine, Kasturba Medical College, \\ Manipal Academy of Higher Education, Manipal, Karnataka, India \\ Address for correspondence Dr. Chandni Gupta, MBBS, MD, \\ Department of Anatomy, Kasturba Medical College, Manipal 576104 \\ Karnataka, India (e-mail: chandnipalimar@gmail.com). \\ J Morphol Sci 2018;35:261-265.
}

\begin{abstract}
Keywords

- carotid canal

- shape

- neurosurgeons

- base of skull

- foramen magnum

Background and Objective The carotid canal (CC) is a bent passage in the petrous temporal bone from where the internal carotid artery (ICA) goes inside the skull. The shape, location and measurements of the CC are clinically very important in cases of skull base surgery, since the ICA has to be identified and isolated throughout its petrous course. Therefore, the present study was performed to measure and locate the CC from various important anatomical landmarks.

Materials and Method The present study was conducted on 68 dry skulls of unknown gender. Various measurements and distances of the CC from various important landmarks were taken. The shape of the CC was also noted. Measurements were taken with the help of a screw-adjusted compass and of digital Vernier calipers. From the above measurements, mean and standard deviation (mean \pm SD), median, range, and mode were calculated. Data analysis was done with IBM SPSS Statistics for Windows, Version 19.0 (IBM Corp, Armonk, NY, USA).

Results The mean length of the CC on the right and left sides was 7.76 and $7.89 \mathrm{~mm}$, respectively. The mean breadth of the CC on the right and left sides was 5.81 and $6.32 \mathrm{~mm}$, respectively. The most common shape of the CC was round both on the right and left sides in $49.20 \%$ and in $53.12 \%$ of the cases.

Conclusion The results of the present study will be useful in the performance of neurosurgical procedures, thereby preventing unpleasant complications.
\end{abstract}

\section{Introduction}

The carotid canal (CC) is a large, almost circular foramen through the petrous part of the temporal bone, through which the large vessel internal carotid artery (ICA), along with accompanying plexuses of veins and some autonomic nerves are transmitted. The external aperture of the carotid canal (EACC) is seen on the undersurface of the petrous part of the temporal bone, posterolateral to the foramen lacerum and anterolateral to the jugular foramen. ${ }^{1,2}$ Starting from the EACC, the $\mathrm{CC}$ runs up for a distance of $1 \mathrm{~cm}$ and then bends at

received

August 3, 2018

accepted

November 2, 2018
DOI https://doi.org/ ISSN 2177-0298. 10.1055/s-0038-1676540. around $90^{\circ}$. The CC turns forward and toward the medial side, up to the apex of the petrous part of the temporal bone for about 2 to $3 \mathrm{~cm}$ and then ends, forming the internal aperture of the carotid canal (IACC). This opening is found in front of the foramen lacerum, and the ICA enters the cranial cavity. The ICA is separated from the walls of the CC by the internal carotid venous plexus and by some perivascular tissue. $^{3}$

Measurements of the base of the skull in adults have been performed by very few investigators. Some previous researchers have studied the IACC, while some have also
Copyright @ 2018 by Thieme Revinter Publicações Ltda, Rio de Janeiro, Brazil
License terms

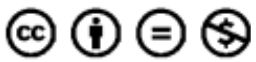


measured the size of the $\mathrm{CC}$ in adults along with measurements of the angles of the internal bend of the CC. Normal and abnormal findings regarding the foramina of the skull can be revealed by investigations such as computed tomography (CT) and magnetic resonance tomography (MRT). Precise information about the anatomy of the base of the skull has become critical as various microsurgeries have been employed for certain tumors and aneurysms. ${ }^{4}$ The present study can provide data to neuroradiologists and neurosurgeons about the comparison of the measurements of the base of the skull. The CC was selected as the landmark as it is the most important and easily identifiable structures on MRT and on digital subtraction angiography (DSA) exams. Therefore, regarding the ICA and its associated anomalies, we intend to give population-specific details of the CC which would assist neurosurgeons to improve different surgical approaches to the second part of the ICA i.e petrous part.

\section{Materials and Methods}

A total of 68 dry skulls of unknown gender were used for the present study. Skulls which were damaged, fractured or deformed at the surroundings of the CC were eliminated from the study. The following parameters were measured:

(-Figs. 1 and 2)

1. Anteroposterior diameter of the $\mathrm{CC}(\mathrm{L})$

2. Transverse diameter of the CC (B)

3. Shortest distance from the $\mathrm{CC}$ to the external acoustic meatus (EAM).

4. Shortest distance from the tubercle of root of zygoma (ZA) to the $\mathrm{CC}$

5. Shortest distance from the tip of the mastoid process (MP) to the $\mathrm{CC}$

6. Shortest distance from foramen magnum (FM) to the CC

7. Shortest distance from the occipital condyle (OC) to the CC

8. Shortest distance from the midline of the base of the skull (Mid) to the CC

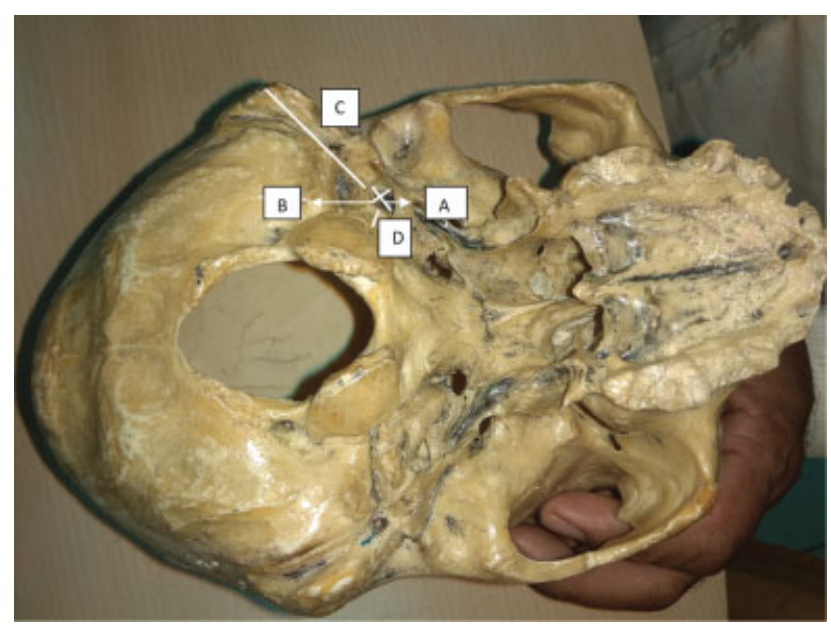

Fig. 1 Measurements done on the carotid canal (CC). (A) Anteroposterior diameter of the CC; (B) transverse diameter of the CC; (C) shortest distance from the tip of the mastoid process (MP) to the CC; and (D) shortest distance from the occipital condyle (OC) to the CC.

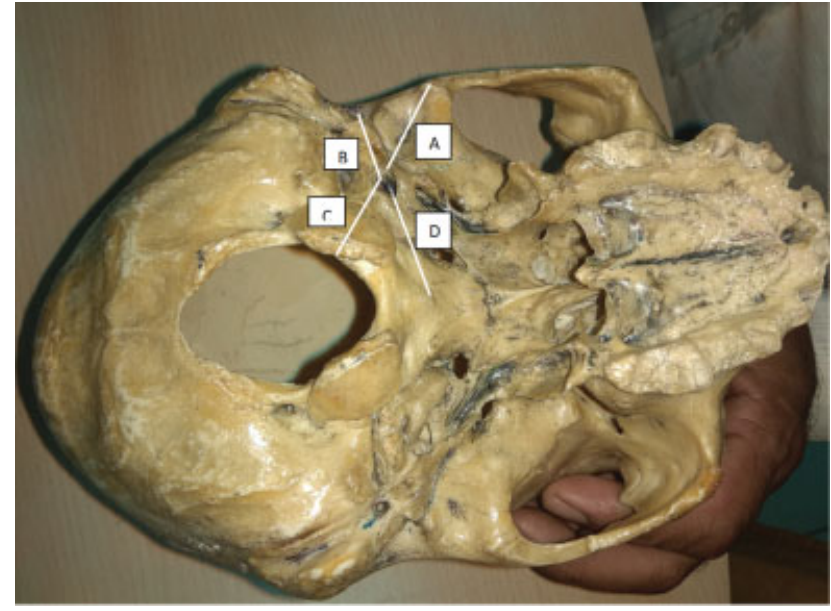

Fig. 2 Measurements done on the carotid canal (CC). (A) Shortest distance from the tubercle of root of zygoma (ZA) to the CC; (B) shortest distance from the $C C$ to the external acoustic meatus (EAM); (C) shortest distance from the foramen magnum (FM) to the CC; and (D) shortest distance from the midline of the base of the skull (Mid) to the CC.

The shape of the CC was also noted. All of the measurements were taken on both sides. The measurements were taken with the help of a screw-adjusted compass and of digital Vernier calipers. All of the measurements were taken three times by the same person in order to increase the accuracy of the measurements.

\section{Statistical Analysis}

From the above measurements, mean and standard deviation (mean $\pm \mathrm{SD}$ ), median, range, and mode were calculated. The data analysis was performed with IBM SPSS Statistics for Windows, Version 19.0 (IBM Corp, Armonk, NY, USA), and $p<0.05$ was considered statistically significant.

\section{Results}

A total of 68 skulls were examined. Five skulls were not examined on the right side, and four were not examined on the left side due to destruction. Therefore, the total number of sides examined was 127 .

The results of the measurements of the CC are shown in -Table 1.

The mean, median, and range of the distances from the CC to various important anatomical landmarks were tabulated as shown in - Table 2.

The various shapes of the $\mathrm{CC}$ were noted down and tabulated in - Table 3. (-Fig. 3 )

\section{Discussion}

The ICA arises from the common carotid as a bifurcation at the superior border of the thyroid cartilage opposite to the disc between the C3 and C4 vertebrae. Each artery passes upward through the neck within the carotid sheath, toward the brain. The artery is divided into four parts along its course: the cervical, petrous, cavernous, and cerebral parts. 
Table 1 Measurements of the carotid canal

\begin{tabular}{|l|l|l|l|l|l|l|l|l|l|}
\hline Dimension & \multicolumn{2}{|l|}{ Mean \pm SD } & p-value & \multicolumn{2}{l|}{ Median } & \multicolumn{2}{l|}{ Range } & \multicolumn{2}{l|}{ Mode } \\
\hline & Right & Left & & Right & Left & Right & Left & Right & Left \\
\hline Length $(\mathrm{mm})$ & $7.76 \pm 0.88$ & $7.89 \pm 0.88$ & 0.395 & 7.9 & 8.0 & $6.0-10.0$ & $5.5-10.5$ & 8.0 & 8.0 \\
\hline Breadth $(\mathrm{mm})$ & $5.81 \pm 0.71$ & $6.32 \pm 0.80$ & 0.002 & 6.0 & 6.0 & $4.5-7.5$ & $4.5-8.0$ & 6.0 & 6.0 \\
\hline
\end{tabular}

Abbreviations: SD, standard deviation.

Table 2 Mean, median and range of the distances from the carotid canal to various important anatomical landmarks

\begin{tabular}{|l|l|l|l|l|l|l|l|l|l|}
\hline Dimension & \multicolumn{2}{|l}{ Mean \pm SD } & p-value & \multicolumn{2}{l|}{ Median } & \multicolumn{2}{l|}{ Range } & Mode \\
\hline & Right & Left & & Right & Left & Right & Left & Right & Left \\
\hline CC-EAM & $20.24 \pm 2.47$ & $20.50 \pm 4.05$ & 0.602 & 20.5 & 20.5 & $14.5-26.0$ & $15.1-45.0$ & 21.0 & 21.0 \\
\hline CC-ZA & $44.91 \pm 3.17$ & $44.64 \pm 3.67$ & 0.621 & 45.0 & 45.0 & $38.0-53.0$ & $35.0-53.0$ & 45.0 & 45.0 \\
\hline CC-MP & $30.04 \pm 3.10$ & $30.41 \pm 3.57$ & 0.578 & 30.0 & 31.0 & $24.0-36.5$ & $23.5-38.0$ & 30.0 & 32.0 \\
\hline CC-FM & $27.16 \pm 2.92$ & $27.08 \pm 2.72$ & 0.927 & 27.0 & 27.0 & $22.0-37.0$ & $21.0-36.5$ & 27.0 & 27.0 \\
\hline CC-OC & $22.15 \pm 2.57$ & $22.461 \pm 2.60$ & 0.482 & 22.0 & 23.0 & $17.0-29.0$ & $20.0-30.0$ & 25.0 & 27.0 \\
\hline CC-Midline & $26.41 \pm 2.72$ & $25.93 \pm 2.33$ & 0.242 & 26.0 & 26.0 & $21.0-33.2$ & $20.0-30.0$ & 25.0 & 27.0 \\
\hline
\end{tabular}

Abbreviations: CC, carotid canal; EAM, external acoustic meatus; FM, foramen magnum; MP, mastoid process; OC, occipital condyle; SD, standard deviation; ZA, tubercle of root of zygoma.

Table 3 Various shapes of the carotid canal

\begin{tabular}{|l|l|l|l|}
\hline Shape & $\begin{array}{l}\text { Right } \\
(\boldsymbol{n}=\mathbf{6 3 )}\end{array}$ & $\begin{array}{l}\text { Left } \\
(\boldsymbol{n}=\mathbf{6 4})\end{array}$ & $\begin{array}{l}\text { Total } \\
(\boldsymbol{n}=\mathbf{1 2 7})\end{array}$ \\
\hline Round & $31(49.206 \%)$ & $34(53.125 \%)$ & $65(51.181 \%)$ \\
\hline Oval & $20(31.746 \%)$ & $17(26.563 \%)$ & $37(29.134 \%)$ \\
\hline Almond & $12(19.048 \%)$ & $12(18.75 \%)$ & $24(18.898 \%)$ \\
\hline
\end{tabular}

The ICA traverses the petrous part of the temporal bone in the $\mathrm{CC}$, in which it first passes upward along the anterior wall of the middle ear cavity and the cochlea of the internal ear, and then curves forward and medially below the auditory tube and the trigeminal ganglion. It enters the cranial cavity through the apex of the petrous temporal bone in the posterior wall of the foramen lacerum. ${ }^{5}$

Fractures of the base of the skull are commonly associated with carotid artery injuries, and vascular complications are more frequently observed when the $\mathrm{CC}$ is involved. Fractures at the petrous part of the CC are associated with a relatively high incidence of injury to the carotid artery, and patients suffer more severe head injuries. ${ }^{6}$ In $<0.01 \%$ of the population, rare congenital anomalies like a non-formed or a poorly formed ICA can be seen. However, agenesis of the ICA is usually asymptomatic and is usually found as an incidental finding or after a cerebrovascular accident, such as

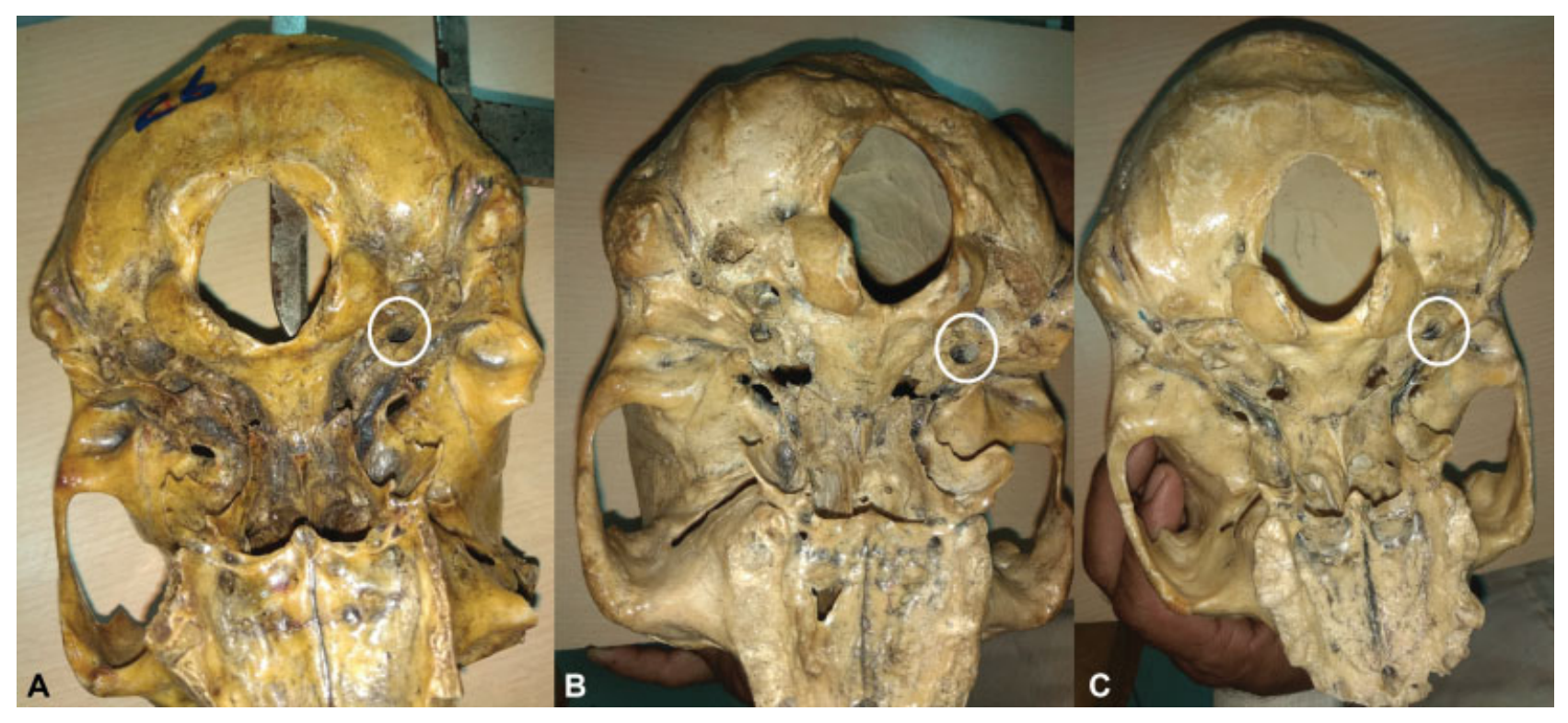

Fig. 3 Shapes of the carotid canal. (A) Oval-shaped; (B) round-shaped; and (C) almond-shaped. 
subarachnoid hemorrhage after a coincidental rupture of an aneurysm, or cerebral infarction. ${ }^{7,8}$ This is commonly seen unilaterally; however, bilateral absence has been reported. Also, the estimated prevalence of cerebral aneurysms in association with agenesis of ICA is of between 24 and 34\% in the general population, and recognizing this anomaly is of great value in thromboembolic cases. ${ }^{7}$ Although the exact cause of these developmental anomalies is not known, the evaluation of the base of the skull for the absence or presence of the $\mathrm{CC}$ is required to differentiate agenesis and aplasia, as the prerequisite for the development of the $\mathrm{CC}$ is the presence of a precursor of the ICA or of the ICA itself at a gestational age of 5 to 6 weeks. This development of the bony CC represents the development of the ICA, which may end as the stenosis of the ICA begins and poorly formed bony carotid canal can be seen in adult onset moyamoya disease patients. ${ }^{9}$

During the intrauterine development, before the mesenchymal condensation starts to initiate to form the cranial cartilages, the major cranial blood vessels and nerves are already formed. Therefore, the foramina of the skull are specifically placed even before the formation of bones. Mesenchymal chondrogenesis around the carotid artery joins each hypophysial cartilage to the otic capsule, to form the CC.

Congenital agenesis of one or both ICAs has a very high association with aneurysm formation in the circle of Willis, and since the CCs in the skull base form after the formation of the embryonic ICA, agenesis, aplasia or hypoplasia of a CC on a computed tomography (CT) scan of the base of the skull would suggest a congenital abnormality in the ICA and hint at an investigation for any other associated intracranial vascular abnormalities, even in a young or asymptomatic patient. ${ }^{10}$ Therefore, the present study was conducted to provide some data on the differences in the morphology of the bilateral vascular opening for the ICA, which is the CC. Regarding the ICA, the importance of measurements of the CC has been previously estimated by various authors with the aim to improve various surgical approaches to this part of the ICA. ${ }^{11}$ There is a rapid development of the bony structure of the CC before around the age of two years old, and after the bony suture fuses, the development slows down. Also, the inexistence of the anteroinferior wall of the CC bilaterally was first reported in 1896. The absence or the deficiency of the inferior wall of the $\mathrm{CC}$ is a vital disparity which can lead to complications in surgeries of the base of the skull. ${ }^{12}$ Previous studies have reported the absence of the inferior wall of the CC, which had an incidence of only 1 in 325 cases, while in other studies, 5 cases were found in 307 skulls. ${ }^{13,14}$

The measurements of the $\mathrm{CC}$ are noted in previous studies, such as the one by Watanabe et al., and the transverse diameter in normal Japanese adults was of $5.27 \pm 0.62 \mathrm{~mm}$, whereas it was shorter $(3.31 \pm 0.44 \mathrm{~mm})$ in patients with adult-onset moyamoya disease with ICA stenosis. ${ }^{9}$

The comparison of our parameters with the parameters of other authors is shown in - Tables 4, 5 and 6.,15-17

Calguner et al have also obtained measurements of CCs from 307 dry skulls, including 177 adult male and 130 adult female skulls, and the values of the mean anteroposterior
Table 4 Comparison of the mean transverse diameter of the carotid canal

\begin{tabular}{|c|c|c|c|}
\hline \multicolumn{2}{|l|}{ Study } & Right side & Left side \\
\hline \multicolumn{2}{|c|}{ Somesh et $\mathrm{al}^{5}$} & $6.310 \pm 0.641$ & $6.195 \pm 0.804$ \\
\hline \multicolumn{2}{|c|}{ Ahmed et al ${ }^{15}$} & 5.54 & 5.27 \\
\hline \multirow[t]{2}{*}{$\begin{array}{l}\text { Shaikh } \\
\text { et al }^{16}\end{array}$} & $\begin{array}{l}\text { Male } \\
(>25 \text { years } \\
\text { old })\end{array}$ & $5.33 \pm 0.8$ & $5.46 \pm 0.8$ \\
\hline & $\begin{array}{l}\text { Female } \\
(<25 \text { years } \\
\text { old })\end{array}$ & $5.3 \pm 1.23$ & $5.25 \pm 0.81$ \\
\hline \multirow{2}{*}{$\begin{array}{l}\text { Abo } \\
\text { et al }\end{array}$} & Male & $5.7 \pm 0.69$ & $5.58 \pm 0.67$ \\
\hline & Female & $5.0 \pm 0.5$ & $4.86 \pm 0.44$ \\
\hline \multicolumn{2}{|c|}{ Present study } & $5.81 \pm 0.71$ & $6.32 \pm 0.80$ \\
\hline
\end{tabular}

diameter of the carotid canal were $6.82 \pm 1.56$ and $6.50 \pm 1.46$ (Mean \pm SEM) on the right and left sides of male skulls, respectively. In the female skulls, these values were $6.68 \pm 1.18$ and $6.30 \pm 1.05$ on the right and left side,

Table 5 Comparison of the mean anteroposterior diameter of the carotid canal

\begin{tabular}{|l|l|l|l|}
\hline \multicolumn{2}{|l|}{ Study } & Right side & Left side \\
\hline \multicolumn{2}{|l|}{ Somesh et al } & \\
\hline \multicolumn{2}{|l|}{ Ahmed et al } & $8.128 \pm 0.990$ & $8.158 \pm 1.002$ \\
\hline $\begin{array}{l}\text { Shaikh } \\
\text { et al }^{16}\end{array}$ & $\begin{array}{l}\text { Male } \\
(>25 \text { years } \\
\text { old })\end{array}$ & 6.795 & 6.285 \\
\cline { 2 - 4 } & $\begin{array}{l}\text { Female } \\
(<25 \text { years } \\
\text { old })\end{array}$ & $7.0 \pm 0.65$ & $7.26 \pm 1.03$ \\
\hline $\begin{array}{l}\text { Abo } \\
\text { et al }\end{array}$ & Male & $7.96 \pm 0.89$ & $6.77 \pm 0.8$ \\
\cline { 2 - 4 } & Female & $7.0 \pm 0.65$ & $6.77 \pm 0.6$ \\
\hline \multicolumn{2}{|l|}{ Present study } & $7.76 \pm 0.88$ & $7.89 \pm 0.88$ \\
\hline
\end{tabular}

Table 6 Comparison of mean distance between the center of the carotid canal and the midsagittal plane

\begin{tabular}{|c|c|c|c|}
\hline \multicolumn{2}{|l|}{ Study } & Right side & Left side \\
\hline \multicolumn{2}{|c|}{$\begin{array}{l}\text { Somesh et al (medial } \\
\text { edge) }\end{array}$} & $25.42 \pm 0.250$ & $24.97 \pm 0.250$ \\
\hline \multicolumn{2}{|c|}{ Ahmed et al ${ }^{15}$} & 26.14 & 26.02 \\
\hline \multirow[t]{2}{*}{$\begin{array}{l}\text { Shaikh } \\
\text { et al }\end{array}$} & $\begin{array}{l}\text { Male } \\
\text { (>25 years } \\
\text { old) }\end{array}$ & $24.31 \pm 2.61$ & $24.74 \pm 3.08$ \\
\hline & $\begin{array}{l}\text { Female } \\
\text { (>25 years } \\
\text { old) }\end{array}$ & $23.68 \pm 2.83$ & $24.29 \pm 2.62$ \\
\hline \multirow{2}{*}{$\begin{array}{l}\text { Abo } \\
\text { et } \mathrm{al}^{17}\end{array}$} & Male & $28.78 \pm 2.15$ & $28.19 \pm 1.97$ \\
\hline & Female & $26.4 \pm 1.4$ & $25.99 \pm 1.5$ \\
\hline \multicolumn{2}{|c|}{ Present study } & $26.41 \pm 2.72$ & $25.93 \pm 2.33$ \\
\hline
\end{tabular}


respectively. The mean transverse diameter on the right and left side of male skulls were $4.86 \pm 2.34$ and $4.60 \pm 1.05$, respectively. In the female skulls, these values were $4.59 \pm 0.87$ and $4.33 \pm 0.91$ on the right and left side, respectively. ${ }^{13}$ In another study by Lang et al, the mean anteroposterior diameter of the CC was $5.08 \pm 0.20$ and $5.20 \pm 0.34$ on the right and left sides of the skulls, respectively. However, in both of these previous studies, the measurements of the anteroposterior (long) diameter and of the transverse (short) diameter of the internal opening of the CC were taken, while in the present study the measurements of the external aperture of the CC were taken. ${ }^{18}$

In a previous study by Calguner et al, the values of the distance from the medial end of the external opening of the $\mathrm{CC}$ to the midsagittal plane are $2.50 \pm 3.59$ and $24.92 \pm 2.45$ on the left and right sides for females, respectively, and $25.63 \pm 3.60$ and $25.67 \pm 2.88$ on the left and right sides for males, respectively. ${ }^{13}$ In another study by Lang et al, these values were $20.50 \pm 0.50$ and $24.25 \pm 0.75$ on the left and right sides, respectively. ${ }^{12}$

\section{Conclusion}

Our study provides important information about the site of the CC using various anatomical landmarks surrounding it in the bases of the skulls of adult Indians. These linear dimensions will facilitate neurosurgical procedures, thereby preventing unpleasant complications.

\section{Conflicts of Interests}

We state that we did not receive any financial funding from any agencies. The authors have no conflicts of interests to declare.

\section{References}

1 Berkoviz BK, Moxham BJ. Textbook of Head and Neck Anatomy. London: Wolfe Medical Publications; 1988:1-33

2 Standring S. The Anatomical Basis of Clinical Practice. In: Standing S, editor-in-chief, Gray‘s Anatomy. 39th ed. London: Elsevier Limited; 2006:460-465

3 Sprinzl GM, Mockenhaupt J, Koebke J, Thumfart WF. [The temporal bone]. HNO 1992;40(06):206-214
4 Lang J, Hack C. Uber Lage und Lagevariationen der Kanalsysteme im Os temporale. Teil I. Kanäle der Pars petrosa zwischen Margo superior und Meatus acusticus internus. HNO 1985;33(04): 176-179

5 Somesh S, Sridevi HB, Murlimanju BV, Shakunthala P. Morphological and Morphometric study of carotid canal in Indian Population. Int J Biomed Res 2014;5(07):455-460

6 Resnick DK, Subach BR, Marion DW. The significance of carotid canal involvement in basilar cranial fracture. Neurosurgery 1997; 40(06):1177-1181

7 Given CA II, Huang-Hellinger F, Baker MD, Chepuri NB, Morris PP. Congenital absence of the internal carotid artery: case reports and review of the collateral circulation. AJNR Am J Neuroradiol 2001; 22(10):1953-1959

8 Florio F, Balzano S, Nardella M, et al. Congenital absence of the internal carotid artery. Cardiovasc Intervent Radiol 1999;22(01): 74-78

9 Watanabe A, Omata T, Koizumi H, Nakano S, Takeuchi N, Kinouchi H. Bony carotid canal hypoplasia in patients with moyamoya disease. J Neurosurg Pediatr 2010;5(06):591-594

10 Quint DJ, Boulos RS, Spera TD. Congenital absence of the cervical and petrous internal carotid artery with intercavernous anastomosis. AJNR Am J Neuroradiol 1989;10(02):435-439

11 Aslan A, Balyan FR, Taibah A, Sanna M. Anatomic relationships between surgical landmarks in type $b$ and type $c$ infratemporal fossa approaches. Eur Arch Otorhinolaryngol 1998;255(05): 259-264

12 Lang J, Schafhauser O, Hoffmann S. Uber die postnatale Entwicklung der transbasalen Schädelpforten: Canalis caroticus, Foramen jugulare, Canalis hypoglossalis, Canalis condylaris und Foramen magnum. Anat Anz 1983;153(04):315-357(lena)

13 Calgüner E, Turgut HB, Gözil R, Tunç E, Sevim A, Keskil S. Measurements of the carotid canal in skulls from Anatolia. Acta Anat (Basel) 1997;158(02):130-132

14 Sharma PK, Lakhtakia PK, Bisaria KK. A variant of the floor of the carotid canal. Ann Anat 1993;175(02):199

15 Ahmed MM, Jeelani M, Tarnum A. Anthropometry: A Comparative Study of Right and Left Sided Foramen Ovale, Jugular Foramen and Carotid Canal. Int J Sci Stud 2015;3(05):88-94

16 Shaikh VG, Kulkarni PR. A study of morphology, morphometry, symmetry and development of external opening of carotid canal with comparison in male, female and foetus. Int J Anat Res. 2014;2 (04):797-805

17 Abo AM, Ashraf Y, Adel N, Abdel M. Morphometric Study of the Carotid Canal. Life Sci J 2013;10(10):2559-2562

18 Lang J, Schreiber T. Uber Form und Lage des Foramen jugulare (Fossa jugularis), des Canalis caroticus und des Foramen stylomastoideum sowie deren postnatale Lageveränderungen. HNO 1983;31(03):80-87 